\title{
On the Dissemination of I.S. Research Findings into Practice
}

\author{
Michael Lang \\ National University of Ireland, Galway \\ Michaet.Lang@nuigatway.ie
}

\begin{abstract}
Because research findings often do not have direct or immediate relevance to practitioners, the question arises as to how those findings should be disseminated to them in a suitable form at such time as they do become relevant. A central argument of this paper is that the traditional mechanisms whereby IS researchers disseminate their work are prone to numerous communication breakdowns, and that much work which could potentially make valuable contributions to practice is haplessly lost within the vaults of academia. Using the well-known Shannon \& Weaver communication model, three major problems are analysed: the choice of dissemination channels, language barriers, and the alienation of academia from industry. It is then argued that these problems are primarily caused by deep-rooted institutionalised norms, and the enduring absence of a cumulative tradition within IS research. A number of suggested reforms are presented.
\end{abstract}

Keywords: IS Research Relevance; Communication of IS Research

\section{Introduction}

academic / adj. \& n.

"4. Not leading to a decision; unpractical; theoretical, formal, or conventional."

"5. Conforming too rigidly to the principles of an academy; excessively formal."

- Oxford English Dictionary (http://dictionary.oed.com)

It is often interesting to observe how the meaning of a word as ascribed to it in everyday use may over time gradually but radically diverge from its etymological origins. As the above excerpts reveal, the term "academic" is now unfortunately laden with negative connotations of being distant, impractical and irrelevant. Of course, this complaint is not levied at IS academics alone, but as IS is an applied discipline it becomes a more pressing concern.

IS research has two primary objectives; firstly, to build new knowledge, and secondly, to disseminate that knowledge and raise awareness of its potential applications (Kavan, 1998; Moody, 2000). Ultimately, IS research should lead to practical outcomes that are useful to the IS profession and society at large. However, much of what IS academics have to say never reaches the ears of practitioners for a variety of reasons.

Material published as part of these proceedings, either on-line or in print, is copyrighted by Informing Science. Permission to make digital or paper copy of part or all of these works for personal or classroom use is granted without fee provided that the copies are not made or distributed for profit or commercial advantage AND that copies 1) bear this notice in full and 2) give the full citation on the first page. It is permissible to abstract these works so long as credit is given. To copy in all other cases or to republish or to post on a server or to redistribute to lists requires specific permission from the publisher at publister@intormingscience.org
There is a real danger of IS academia becoming withdrawn into itself, not just in the sense that the academic research community is talking only to itself (Keen, 1991), but also, because of the increased unwillingness of practitioners to co-operate in research studies due to perceived lack of relevance, it is becoming all the more common for re- 
On the Dissemination of I.S. Research Findings

search studies to be conducted wholly or partially within university settings.

The evidence that practitioners are ignoring the produce of IS academic researchers is everywhere to be seen. Non-attendance at conferences, falling subscriptions to journals, decreased participation in special interest groups, and growing unwillingness to partake in surveys or other research activities all indicate that IS researchers are losing credibility in the eyes of industry. The loss of practitioners' respect would have serious implications because access to essential commodities such as funding and research sites would come under threat.

The focus of this paper is therefore on the dissemination of research findings to practitioners. As a starting point, relevance is defined and the importance of timeliness is stressed. The paper then uses the classical communication theory framework of Shannon \& Weaver (1949) to discuss problems with dissemination channels, language barriers, and the ill effects of academia's alienation from industry. It is then argued that these problems are primarily caused by institutionalised norms, and the lack of a cumulative research tradition. Finally, a number of recommendations are set forth.

\section{A Definition of "Relevance"}

Amidst all the recent flurry of discussion surrounding IS research relevance, few authors have attempted to explicitly define what is meant by "relevance". It is far too elusive a concept merely to assume that it is self-explanatory in a given context. Generally, it seems that relevance is taken to infer 'immediate and direct applicability to', 'acceptance by', 'use by', 'or intelligibility to' practitioners. For example, Moody (2000) defines relevant research as that which "addresses a practical need", and goes on to state that relevance and utility can only be evaluated by practitioners. Hanseth \& Monteiro (1996) assert that "the relevance of ISD research is intrinsically connected to influencing [i.e. improving] the practice of ISD”, while Saunders (1998) also defines relevance in terms of usefulness to practitioners:

"When research is relevant, managers can use its results to successfully solve critical problems with which they are faced and to use information technology to reshape the environments in which their organizations operate."

However, these definitions are flawed because they do not explicitly recognise that: firstly, practitioners are not the sole consumers, often not the primary consumers, and frequently not even intended to be consumers at all, of IS research; and secondly, it is inconceivable that relevance can be defined without reference to the component of time.

To elaborate the first of these points, there are a variety of distinct stakeholders in the IS research production process, each with different value systems, needs and expectations (Dennis, 2001; Keen, 1991; Khazanchi \& Munkvold, 2001). These include practitioners, students, educators, researchers, consultants, and scholars in other disciplines. The non-acceptance or non-utilisation by practitioners of academic IS research should therefore not always be regarded as a true and fair indicator of its relevance (Lee, 1999a). Indeed, much of the work that academic researchers produce is of a highly esoteric or theoretical nature and is intended to be of immediate relevance only to other researchers working within the same domain (Harel, 1997; Cresswell, 2001). Naturally, what practitioners expect and want are unambiguous, implementable resolutions to real and immediate problems, rather than a purely academic contribution that fills some gap in a theoretical body of knowledge. This explains why practitioners are often disenchanted with the outcome of academic research projects that they sponsor.

A second key aspect in defining "relevance" is that of timeliness. Very often, the theoretical bases upon which research is founded may be of little or no practical use when initially published, therefore contemporaries are not always well placed to judge its relevance (Kock et al., 2001). In reality, academic researchers are unlikely to make a worthy contribution to practice in less than 5 years (Lyytinen, 1999). It may thus be argued that to be truly relevant, IS research must be future-oriented (Rollier, 2001; Dennis, 
2001). Research with a long-term perspective is often not directly relevant to practitioners in its initial stages, but it may become so through the gradual accumulation of small but significant advances that eventually enable the resolution of major problems. A case in point here is that of Vannevar Bush, whose futuristic "As We May Think" essay published in Atlantic Monthly in July 1945 formed the basis of Engelbart's work into the "augmentation of man's intellect" throughout the 1960s, which in turn blossomed into significant advances in graphical user interfaces, computer-supported cooperative work, hypermedia, organizational memory, information retrieval, Intranets, and knowledge management. In many cases it is inappropriate to fix a timescale - be it 5, 10, 15, or more years - until practical outcomes are achieved, if ever. Thus, "relevance" is a highly transient concept, and different time frames can lead to completely different judgements about the relevance and value of research.

By its very nature, theory-building work or basic research may be abandoned before reaching some tangible fruition if critical or chronic flaws cause it to fall down. However, such work should not be abruptly dismissed as irrelevant. So long as its objective is to produce a contribution to knowledge that is intended either directly or indirectly to eventually lead to a valuable contribution to practice, then it is fair to consider the work as being relevant, even if it drops short. Lessons can be drawn from such failures so that future attempts to resolve the issue are embellished.

Researchers whose selected area is topical only within the short or medium-term face the unenviable prospect that the effluxion of time may render their findings obsolete before they are even published. In this regard, the long production cycles of academic journal articles, typically of the order of 5 years (spe-

cial issues excepted), is not helpful. Academic writers seek to circumvent this problem by aspiring, unlike the trade press, to produce timeless contributions (Lee, 1999b). Nevertheless, it would be arrogant and foolish to suggest that IS research is immune to long publication delays, because of the inherent dynamism of IS infrastructures (Ives, 1993). It is artificial to divorce the management of IT from IT itself, because technology can and does alter the environment.

As basic research matures and theories are iteratively refined, they attain direct and immediate relevance to practitioners. Furthermore, "old" theories can often be reframed in "new" modern contexts (Keen, 1991; Lee, 1999b), so that for example, end-user computing theory can be reapplied to Intranet rollouts, and experiences with EDI can assist B2B XML systems. It should not be left to practitioners to attempt to make these sometimes tenuous connections. Once IS research becomes relevant to practitioners' needs, it is incumbent upon academia to communicate it to them "in the language and through the media of practice" (Senn, 1998). At present, that duty is woefully neglected.

\section{Synopsis of Communication Problems}

The process of human communication commences when an individual starts to encode thoughts into a language that is understandable by others. Once encoded, the message is then transmitted via one or more channels to the intended recipient. Upon receipt, the message is decoded and interpreted; this presupposes that the sender and the recipient use a common, shared language (Ellis \& McClintock, 1990). This process is illustrated by the model presented in Figure 1, an adaptation of the well-known framework proposed by Shannon and Weaver (1949). Although deliberately simplified, this model nevertheless provides a useful basis upon which to reason about difficulties in communicating IS research findings.

Three critical aspects of an effective communication system are that: firstly, suitable communication channels are selected, with minimal noise; secondly, the language of communication is intelligible to both parties; and thirdly, the participants in the communication come from similar environments, or at least have had adequate exposure to each others environments. In all three of these aspects, the means by which IS research findings have traditionally been relayed to practitioners are chronically impaired. Each of these is now discussed in turn. 


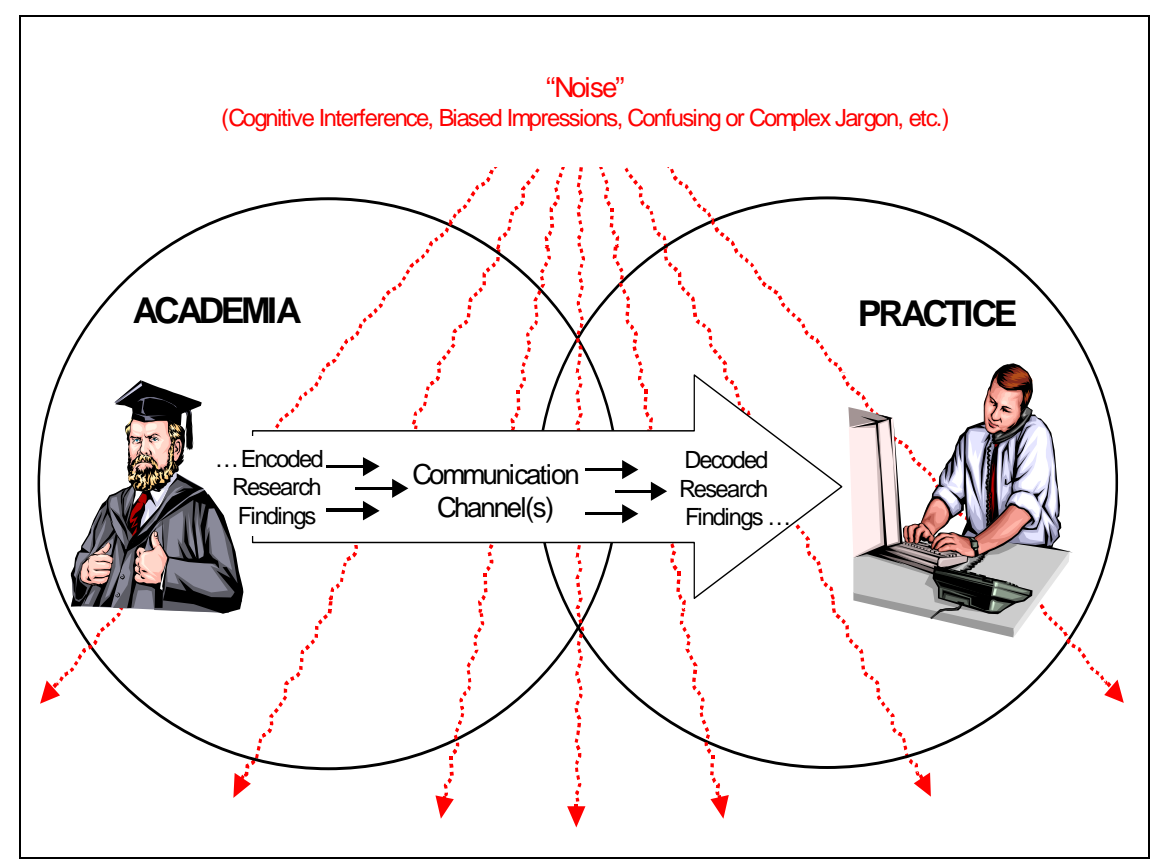

Figure 1. Basic Model of Human Communication.

\section{Dissemination Channels}

Figure 2 presents a schema of the information sources to which various stakeholders in the IS research production process refer and submit to. Notably, the channels that academics primarily use - scholarly journals and academic conferences - are not targeted by practitioners (Kavan, 1998; Senn, 1998; Davenport, 1997). Thus, Keen (1991) challenges the traditional assumption that journals should be the main outlet for IS research on the basis that it is "highly limiting to its progress". Another criticism of journals is that, because of the often dishearteningly low acceptance rates, there is a high level of atrophy. Much promising but "poorly written work" (as defined by academics) may never be disseminated because many researchers respond to journal rejections by abandoning the paper rather than reworking it (Straub et al., 1994). Nevertheless, refereed journals remain second only to refereed conferences as a publication outlet, and journal papers are the most highly regarded in academic promotion and tenure decisions (Avgerou et al., 1999).

It may be argued that academic papers in journals and conferences are not intended for direct consumption by practitioners, and that instead the messages contained therein are meant to be further distilled and transferred through other media such as teaching and textbooks. The assertion by Olfman (2001) that "research informs textbook writers ... textbooks inform students ... students practice what they learn" is rather simple. In truth, undergraduate teaching is a very slow and inefficient way of disseminating research (Moody, 2000). Of course, it is an altogether different situation if providing part-time postgraduate teaching to professionals, and that is much more likely to be an effective means of disseminating research findings. However, even then, the intrinsic irony is that academics tend to refer to articles from practitioner periodicals more so than articles from scholarly journals in the preparation of course materials, - thus flaunting the respective merit values that are entrenched in academic reward mechanisms. In a recent survey of ISWorld mailing list subscribers, it was revealed that $82.5 \%$ of 137 respondents consider publications such as MIS Quarterly and Journal of the AIS as most important to research, but only $12.4 \%$ said that those same sources were most important for teaching, for which purpose practitioner publications are seen as being far more useful (Press, 2001). This practice is slammed as being downright hypocritical by Robey \& Markus (1998) who insist that academics be forced to "eat [their] own dog food". 


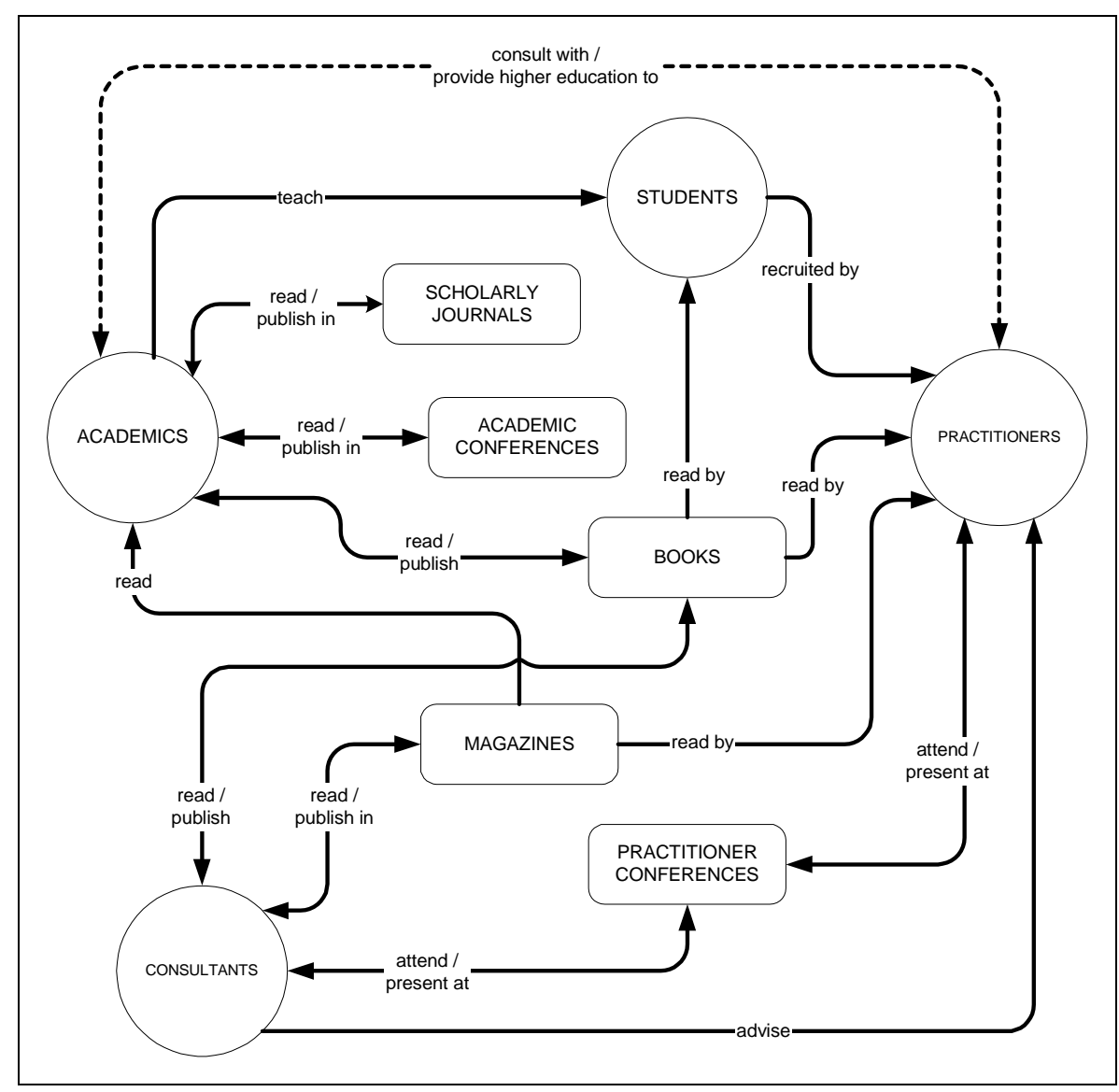

Figure 2. Communication Flows in Dissemination of Research Results.

As a publication outlet, books are much more influential than scholarly journals or academic conferences and can play a very important role in advancing a discipline by providing or stimulating provocative insights that may shape future thinking (Lyytinen, 1999; Keen, 1991). Again however, books are not as favoured as journal articles in academic reward mechanisms, the effort required to produce them being entirely disproportionate to the recognition granted (Gillenson \& Stutz, 1991). This seems less true in certain regions, such as Scandinavia and German-speaking nations of Europe, where a stronger "book culture" has been observed (Avgerou et al., 1999).

In light of these communicational problems, a number of recommendations have been set forth. Foremost amongst these is that academics should support practitioners outlets, and make academic outlets more accessible to practitioners, perhaps by providing separate editions for different audiences (Alter, 2001; Davenport \& Markus, 1999; Robey \& Markus, 1998; Westfall, 1999). Alone amongst the leading IS journals, Communications of the ACM bears the enviable distinction of being highly respected by both the academic community and the practitioner community (Holsapple et al., 1994; Walstrom et al., 1995; Whitman et al., 1999; Mylonopoulos \& Theoharakis, 2001). There is surely room for a few more outlets along the same mould.

Electronic delivery mechanisms also offer much potential. Automated contents notification, the creation of low-cost easily-accessible "e-journals", and moves by traditional journals to provide on-line access to indexed archives all facilitate more effective dissemination. Both Westfall (2001) and Senn (1998) suggest that researchers should use electronic methods to package and promote their work in new, nontraditional, practitioner-friendly forms such as reports, briefs, and white papers. Fitzgerald (2001) also calls for Internet-based publishing models in the spirit of the "open source" movement. Although many academics do currently provide free, open, on-line access to their publications, this might be strictly regarded as a flagrant breach of copyright legislation. It is almost ridiculous that academics should author, 
On the Dissemination of I.S. Research Findings

review, and edit articles for no recompense, and then be asked to pay for the finished product and sign away the copyright and redistribution rights. Not surprisingly, there has been an international swell of opinion against this anomaly, leading to the establishment of the Public Library of Science, a not-forprofit organisation that is seeking to freely distribute published articles on-line (http://www.publiclibraryofscience.org).

\section{The Language Barrier}

The second critical prerequisite for successful communication is that the participants are conversant in a commonly understood language. The effective dissemination of IS research findings is greatly hindered by the predilection of academics to use oblique terminology. Indeed, it is common for a discipline with aspirations toward scientific legitimacy to devise its own specialised language, and to use that language as a barrier to entry.

"Like other occult techniques of divination, the statistical method has a private jargon deliberately contrived to obscure its methods from non-practitioners."

\section{- G. O. Ashley}

However, for research to be useful, it must also be usable. At present, the style and form of academic writing is almost impervious to lay persons. Work that is highly relevant to pragmatic issues might be rejected as being irrelevant merely because it is presented in an inaccessible style (Robey \& Markus, 1998). Academics have effectively excluded the practitioner community by paying homage to the dubious virtues of "rigour". Too often, articles are littered with detailed statistics, formalised notations, jargon, arcane prose, and excessive references. The use of terse and complex idioms, perhaps in an attempt to sound clever (as is the wont of academics), serves only to obfuscate the message and lessens the likelihood that it shall be understood. It is not just practitioners who are having difficulty digesting academic papers, but also many within the academic community find it a painful experience (Alter, 2001).

In reviewing academic articles, criteria such as "presentation", "professional style", and "tone" are typically treated as being of low priority, according to a survey of published authors and editorial board members from a selection of leading IS journals (Straub et al., 1994). The authoring guidelines of many of the leading journals do not explicitly talk about style and tone. Not surprisingly, those which target not just the academic community but also the practitioner community do provide explicit directions, - for example, the Harvard Business Review insists that "accessible and jargon-free expression" be used, Communications of the ACM specifies that "articles that are obviously written for a specific niche group or have been written in a dense, theoretical tone will be returned", and IEEE Computer stipulates that "an article

should be comprehensible to all readers, regardless of their speciality". There have been numerous calls to revise norms for style and tone so that articles are shorter, use simple language in so far as is possible, and anchor concepts in realistic examples so as to create appropriate contextual frames (Westfall, 1999; Benbasat \& Zmud, 1999; Kavan, 1998). However, the counterpoint made by Lyytinen (1999) is that several IS phenomena are complex and may therefore demand complex, specialised language; hence, practitioners should be educated to "appreciate brilliant intellectual efforts!" (Which brings to mind a Samuel Beckett quip: "Make sense who may. I switch off.").

\section{Industry and Academia: Polarised Communities}

A key factor in the effectiveness of human communication is the similarity between the "environments" of the sender and the recipient of a message, - that is, the closeness of their respective backgrounds and cumulative experience. The greater the overlap in terms of common knowledge between participants in a communication process, the more effective the communication is likely to be (Ellis \& McClintock, 1990). Unfortunately, there appears to be a major disconnect between academia and industry, as researchers and practitioners have formed their own mutually independent communities, with minimal cross-membership 
and little formal or informal knowledge transfer (Moody, 2000). Thus Glass (1997) is led to comment that "the academic picture of the industrial world (and vice versa) is both skewed and disdainful", while Pike (2000) remarks that "we see a thriving software industry that largely ignores research, and a research community that writes papers rather than software".

Notably, while academics bemoan the absence of practitioners from their conferences and lament that their work is being ignored by industry, few practitioners bother to complain that academia is failing them. Although Robey \& Markus (1998) anticipate an impoverished future for both academics and practitioners if they part, the reality is that practitioners are quite capable of devising their own solutions without recourse to academia. The inverse is not true. Academia does not and cannot exist within a void; however, in many ways it has shut itself away. In the eyes of many practitioners, the only purposeful role that academics fulfil is that of graduate training in routine technical skills, such as programming or analysis and design techniques.

In order for IS research to be of relevance, academics must be exposed to practical contexts (Benbasat \& Zmud, 1999). The reality is that few academics have adequate real-world work experience. By virtue of academic recruitment criteria, this is likely to remain so; professionally inexperienced scholars holding postgraduate research degrees are more likely to be considered eligible for appointment than highly experienced practitioners who perhaps entered industry directly after an undergraduate qualification many years before. Not surprisingly, academics face a credibility gap within the business community, few academics are sought out as being leading thinkers on IT in business, and IT executives feel that in the majority of cases the "academic IS community doesn't have a clue" (Senn, 1998; Benbasat \& Zmud, 1999; Davenport, 1997). It is extremely arrogant of academia to pontificate from their lofty intellectual pedestals, as though somehow they know better how to redress the errant ways of practitioners.

Westfall (2001) warns of the danger whereby research may become an end in itself, with little or no influence on the outside world. Too often, research is driven by researchers' own interests and publication outlets rather than practical needs (Moody, 2000; Lyytinen, 1999). If academics work in isolation, and then try to impose ideas on industry, they are bound to fail (Harel, 1997). IS researchers should therefore look to practice to identify research topics that are likely to be of future interest (Benbasat \& Zmud, 1999). However, herein lies the problem that, traditionally, IT professionals have not been good at communicating their needs to universities (Davenport, 1997).

It is rare for academics and practitioners to work together on projects, so a gulf must be overcome so that researchers may understand what is of use to practitioners, and so that practitioners may understand what benefits can be derived from trying something new (Mead, 2000). Academia has the potential to make valuable contributions to practice through the development of tools, methods, and techniques, but rarely is this potential realised because of ideological differences between the academic and practitioner communities. Numerous suggestions have been made in the literature as to how to bring these two polarised communities closer together; these include: allowing and encouraging academics to take sabbatical leave or career breaks within industry and to engage in consultancy, building alliances with corporations and professional organisations, revising curricula to include professional placements, co-opting practitioners into associate or part-time posts, creating improved knowledge-exchange arenas such as campus industrial parks, reading practitioner periodicals and attending practitioner conferences, engaging in executive education programmes, scheduling "practitioner days" at academic conferences and dispensing with the discriminatory practice of charging premium registration fees to industrial participants at conferences (Saunders, 1998; Khazanchi \& Munkvold, 2001; Moody, 2000; Hanseth \& Monteiro, 1996; Benbasat \& Zmud, 1999).

\section{Identification of Root Causes}

In view of the aforementioned communication issues, and the earlier point that relevance is inextricably bound to timeliness, this section identifies three major impediments to the timely dissemination of research findings to practitioners. Two of these - the over-emphasis on the virtues of "rigour", and academic reward mechanisms - may be regarded as "institutional pressures towards irrelevance" that have 
On the Dissemination of I.S. Research Findings

been perpetuated by "serial hypocrisy" (Davenport \& Markus, 1999; Westfall, 2001; Kock et al., 2001). The third - the lack of a cumulative research tradition - though not institutionalised is nevertheless enduring.

\section{Behind the Fallacy of "Rigour"}

Within academic publishing circles, it seems to be accepted without question that all good quality research is rigorous, and that all rigorous research is of good quality. The emphasis all too often is upon the "how" to study, rather than the "what", "why" and "for whom" (Keen, 1991). In its struggle to achieve legitimacy as a scientific discipline and thus command respect from academic peers, the IS research community has striven for rigour in its work and has relegated relevance as a lesser concern (Moody, 2000; Benbasat \& Zmud, 1999). It seems almost nonsensical that there is an ongoing rigour versus relevance debate, as though these were two mutually exclusive objectives or as though somehow one is more worthy than the other.

Thus far, rigour has been regarded as an absolute concept, and many IS researchers seem blind to its implicit fallacies. The point of the following discourse is not to enumerate all the shortcomings of "rigour", but rather to substantiate the argument that rigour is a false god which is worshipped all too vehemently. To start, the manner in which research is written up is rarely an accurate portrayal of how it was actually done. Hardly ever are all the mistakes, dead ends and backtracking that are an inevitable part of most successful investigations described. Thus Medawar (1963) argues that scientific research articles are fraudulent because they present "a totally misleading narrative of the processes of thought that go into the making of scientific discoveries". This is rather similar to what Parnas \& Clements (1986) in the context of systems development term "faking the process", whereby the documentation is retrospectively fitted to some pre-defined method. Secondly, the methods used by IS researchers are coming under increasing scrutiny, not least because of implicit assumptions that firms and individuals are more alike than different and thus generalisations drawn from comparisons of relatively small samples are dubious (Senn, 1998). Thirdly, as a legacy of the positivist tradition so dominant in North America (and thus propagated by "leading" IS journals), unobservable variables are often ignored rather perilously as being of no consequence. Fourthly, the scientific notion that rigorously conducted studies may be replicated is not feasible in the social sciences, as evidenced by numerous examples of studies investigating the same topic whose findings are mutually irreconcilable (Fitzgerald, 2001).

As the above issues reveal, rigorous research is not always all that it is dressed up to be. The point here is not to espouse the view that researchers should try to be any less rigorous, but rather that the notion of "rigour" can easily be misconstrued and that the trappings of rigour are frequently misused as an excuse to write tersely. Practitioners and other non-academic stakeholders do not understand the intricacies of scientific research methods and techniques, hence it is important to adopt a style and tone that is suitable for communicating findings to them (Robey \& Markus, 1998; Benbasat \& Zmud, 1999). If IS research is to fulfil its mandate of making valuable contributions to society, then funding agencies, journal editors, and influential faculty members shall have to reconsider their postures in the rigour versus relevance debate.

\section{Academic Reward Mechanisms}

For many academics, the primary motivation to conduct research is survival, and the education of practitioners is only a secondary auxiliary objective (Moody, 2000). Lee (2000), in adapting the well-known Porter framework to IS research strategy formulation, speaks of reviewers, editors, faculty members, journal subscribers, and IS managers as "research buyers", and raises the question:

"The very idea of 'research buyers' requires you to ask yourself, 'How am I presenting my research to them so that they would buy it?'” 
Like buyers of any product, practitioners should therefore be expected to avoid journals directed toward a different (i.e. mainly academic) audience; indeed, it seems "almost unreasonable for practitioners to want to read academic articles" (Alter, 2001). Unfortunately, academic appraisal systems guarantee that even those who fail to recognise practitioners as a separate group of customers with different needs shall remain firmly ensconsed within their posts.

Therefore, what needs to be done is no less than a wholesale revision of academic evaluation mechanisms, as academic researchers are otherwise unlikely to change their behaviour in the absence of incentives (Senn, 1998). The problems of attending to "value" and "meaningfulness" in academic appraisal systems are notoriously difficult, and are most apparent in the evaluation of research. One who shrewdly "plays the game" is often given more recognition than one who produces fewer but more valuable publications. Thus Ruth (2000) submits that

“... appraisal systems, no matter how apparently democratic and transparent, by virtue of being systems, remain a techno-rationalistic enterprise that threatens to undermine research".

In particular, the use of journal ranking lists as a basis for tenure and promotion decisions is potentially very damaging. The use of such mechanisms is yet another hangover of the rationalist/positivist tradition, a culture that is firmly grounded in "objective" metrics, - on the pretext that, as mathematics is "the queen of all the sciences, free from any taint of falsity" (attributed to René Descartes), observations drawn from mathematical data have absolute legitimacy. On the contrary, some of the findings of journal ranking studies almost defy belief and it is clear that in many cases they are heavily biased by cultural values and regional identities, and are skewed in favour of the large North American population. As an example, whereas the Information Systems Journal and the European Journal of Information Systems are both very highly respected in Europe (Mylonopoulos \& Theoharakis, 2001; Avgerou et al., 1999), in surveys of North American academics they are relegated to much lower rankings and in some cases are not even ranked at all (Hardgrave \& Walstrom, 1997; Whitman et al., 1999; Mylonopoulos \& Theoharakis, 2001). Conversely, two of the best respected journals in North America, MIS Quarterly and Information Systems Research are unknown to a surprisingly high number of academics in Europe, all the more pronounced in German-speaking regions (Avgerou et al., 1999).

Nevertheless, the tradition of using journal ranking lists as an evaluation mechanism persists strongly in North America, although this practice has not infiltrated Europe to quite the same extent (Mylonopoulos $\&$ Theoharakis, 2001). It may be strongly argued that such use of these ranking lists is tantamount to codifying and propagating a scheme of values, priorities, research agendas and ideologies. It clearly discriminates against those who seek to publish in narrower more-focused journals, as top tier journals are predominantly of rather general scope. Practitioner-oriented periodicals are rarely given credit and are relegated at best to third-tier "C grade" publications, regardless of the much wider readership those publications receive. This is rather condescending towards those outlets, as though they and their readers do not care about the credibility and logical validity of statements. For practitioner publications with wide audiences, their reputations and commercial interests are at stake if poorly informed opinions are broadcast. Notwithstanding, academic evaluation systems ignore and indeed discourage practitioner-oriented forums (Saunders, 1998; Robey \& Markus, 1998; Westfall, 2001). Papers in conference proceedings, though more timely than journal articles, also receive less recognition. Furthermore, the politics of the tenure process ensures that researchers are dissuaded from producing books, even though as forms of publication they are more accessible and potentially much more influential (Keen, 1991; Gillenson \& Stutz, 1991; Whitman et al., 1999). All of these issues reveal how academic appraisal systems perpetuate communication problems by impacting the choice of dissemination channels, and therefore the language and writing style used.

As regards the polarisation of academia and industry, academic appraisal systems are problematic in so far as the development and maintenance of technical competencies, so valued within industry, are neither 
respected nor encouraged. Not surprisingly, universities are experiencing difficulty finding seasoned instructors with the requisite skills to teach courses in newer technologies (Westfall, 1999). There is no incentive for an academic who hails from the era of COBOL and SSADM to learn the "new tricks" of Java, VB, or UML. Indeed, these issues often tend to be rather arrogantly dismissed as mere "technical" concerns on the basis of such erudite claims as "all programming languages are basically the same". Academics who maintain their technical skills may in fact be indirectly penalised if by investing time in so doing, they are distracted from research activities. It is therefore no surprise that, upon entering academia, gaps in technical skills soon appear. As a consequence much of what is taught is obsolete. Because of this skills gap, academics lose credibility in the eyes of practitioners.

In light of these issues, there have been calls to re-evaluate tenure criteria, include technical competencies in appraisal schemes, reward publishing in practitioner-oriented outlets, and possibly provide for faculty careers along either a "research track" or a "technology track" (Westfall, 1999; Saunders, 1998; Paper, 2001).

\section{The "Lost Volumes": Failure to Build Upon Existing Knowledge}

The lack of a cumulative tradition within IS research is oft lamented (Keen, 1991; Benbasat \& Zmud, 1999), though never really from the perspective of disseminating IS research findings. There are dissenting voices who argue that a cumulative tradition may actually hinder relevance in an era of rapid change, as it may not be appropriate to apply knowledge about, say, GSS, to emerging technologies (Davenport \& Markus, 1999; Robey \& Markus, 1998). The generally accepted response to this viewpoint is as set forth by Keen (1991):

"A potential Achilles heel of ISR is the assumption of 'newness'. This assumption is most apparent in the more technical areas of research ... In practice, very few of the major areas of concern in ISR are less than twenty years old. Issues seen as 'new' turn out to have long roots."

Lee (1999b) reinforces Keen's point, maintaining that theory and research about the management of IT or the use of IT for managerial and organisational purposes is much less time-sensitive than research on IT itself. It is of course fair to say that if findings can be generalised to subsequent technologies, it may not matter that underlying technologies were superseded. In truth however, articles are not timeless. They are soon forgotten. The average median age of reference lists in IS journals is typically about 5 years (Holsapple et al., 1994).

One way of looking at this lack of a cumulative tradition is as the failure of the IS research community to communicate its findings to itself, or to listen to itself. Electronic access to archives and better indexing meta-data can help alleviate this problem, but that of itself is not enough. Far too often, short papers have appeared in journals and conferences alike describing some new method, tool, or technique that has only been tested in narrow case studies (often within academic contexts), but only very rarely do these progress beyond incomplete research prototypes to become commercial realities. Also, many doctoral dissertations remain unpublished in mainstream outlets, or only appear as a disconnected series of papers in various outlets rather than as a cohesive whole. To ensure that the legacy of a research project can be built upon, it is necessary to release the research instruments, research data (subject to confidentiality constraints), software prototypes, full-length reports, and all other artefacts produced as open source objects.

\section{Summary of Implications}

In summary, if IS research findings are to be disseminated in a timely fashion to practitioners, the following recommendations must be acted upon:

- IS researchers must base topic selection on future interests, but in so doing should seek out correlations with topics and technologies of earlier generations, so that "old" theories may be reused where applicable. 
- Publication forums most appropriate to the intended audience of a research project should be employed. For academic stakeholders, these are scholarly journals, academic conferences, and books. For non-academic stakeholders, these are trade periodicals, practitioner conferences, and books.

- Academic reward structures need to be tailored accordingly, so that due recognition is given to publishing practitioner-oriented research in practitioner-oriented forums. Given the much greater potential influence of books over every other paper-based form of publication, greater reward should be given to the publication of peer-reviewed books.

- Academic institutions should develop part-time postgraduate IS programmes geared towards attracting experienced professionals. These may serve as forums for bi-directional exchange of knowledge. IS researchers need to spend more time within industrial contexts, and to be rewarded for maintaining their technical skills.

- IS teachers should refer not just to trade periodicals but also to IS journals in the preparation of course materials.

- Academic writers should use more fluid and open styles, perhaps following the example of those few journals which are held in high regard not just by academia but also by practitioners. Evaluation criteria for IS journals and conferences should be revised to place greater emphasis on relevance and linguistic clarity.

- IS journals need to clear publication backlogs, perhaps by automating electronic workflows or by increasing publication frequencies. In the interests of timely dissemination of scholarly work, academic publishers should be convinced to waive copyright and redistribution regulations for researchers who wish to publish accepted papers on Web servers.

- Academic publishers should provide low-cost access to fully indexed on-line archives.

- IS researchers, on moving to new projects or areas, should permit others to access all artefacts of their work so that legacies may be accumulated upon.

- Research methods and models need to be reconsidered in light of concerns over rigour.

For these recommendations to be enacted shall require a swell of positive support from within the IS community, and a willingness to change itself. Inevitably, this shall necessitate awkward decisions for senior faculty members, who shall be called upon to use their influence to disestablish the same political structures and cultural norms that they used to elevate themselves. Unless the impetus for change comes from the top down, junior researchers shall as is to be expected exhibit behaviour that perpetuates the problems described herein.

\section{References}

Alter, S. (2001) Recognizing the Relevance of IS Research and Broadening the Appeal and Applicability of Future Publications. Communications of the Association for Information Systems. Vol. 6 Article 3, March 2001.

Avgerou, C., Siemer, J. \& Bjørn-Andersen, N. (1999) The academic field of information systems in Europe. European Journal of Information Systems. 8, 136-153.

Benbasat, I. \& Zmud, R. W. (1999) Empirical Research in Information Systems: The Practice of Relevance. MIS Quarterly. Vol. 23 No. 1 March 1999, 3-16.

Cresswell, A. M. (2001) Thoughts on Relevance of IS Research. Communications of the Association for Information Systems. Vol. 6 Article 9, March 2001.

Davenport, T. (1997) Storming the Ivory Tower. CIO Magazine. April 151997.

Davenport, T. H. \& Markus, M. L. (1999) Rigor vs Relevance Revisited: Response to Benbasat and Zmud. MIS Quarterly. Vol. 23 No. 1 March 1999, 19-23. 
On the Dissemination of I.S. Research Findings

Dennis, A. R. (2001) Relevance in Information Systems Research. Communications of the Association for Information Systems. Vol. 6 Article 10, March 2001.

Ellis, R. \& McClintock, A. (1990) If You Take My Meaning: Theory into Practice in Human Communication. Edward Arnold, London.

Fitzgerald, B. (2001) The Gadsby Syndrome in IS Research: Rev. 0.1. National University of Ireland, Cork. http://afis.ucc.ie/bfitzgerald/gadsby/.

Gillenson, M. L. \& Stutz, J. D. (1991) Academic Issues in MIS: Journals and Books. MIS Quarterly. December 1991, 447-452.

Glass, R. L. (1997) Revisiting the industry/academe communication chasm. Communications of the ACM. Vol. 40 No. 6, 1113.

Hanseth, O. \& Monteiro, E. (1996) Navigating Future Research: Judging the Relevance of Information Systems Development Research. Accounting, Management \& Information Technologies. Vol. 6 No. 1/2, 77-85.

Hardgrave, B. C. \& Walstrom, K. A. (1997) Forums for MIS Scholars. Communications of the ACM. Vol. 40 No. 11, 119-124.

Harel, D. (1997) Will I Be Pretty, Will I Be Rich? Some Thoughts on Theory vs Practice in Software Engineering. In Proceedings of IEEE International Symposium on Requirements Engineering, Annapolis, Maryland, USA, January 5-8 1997, pp. 184-186. IEEE Computer Society Press.

Holsapple, C. W., Johnson, L. E., Manakyan, H. \& John, T. (1994) Business Computing Research Journals: A Normalized Citation Analysis. Journal of Management Information Systems. Vol. 11 No. 1, 131-140.

Ives, B. (1993) Cycle-Time Reduction for Disseminating Scholarly Research. MIS Quarterly. June 1993, xxi-xxiii.

Kavan, C. B. (1998) Profit through Knowledge: The Application of Academic Research to Information Technology Organizations. Information Resources Management Journal. Vol. 11 No. 1, 17-22.

Keen, P. G. W. (1991) Relevance and Rigor in Information Systems Research: Improving Quality, Confidence, Cohesion and Impact. In: Information Systems Research: Contemporary Approaches and Emergent Traditions, pp. 27-49. Elsevier Science Publishers (North-Holland),

Khazanchi, D. \& Munkvold, B. E. (2001) Expanding the Notion of Relevance in IS Research: A Proposal and Some Recommendations. Communications of the Association for Information Systems. Vol. 6 Article 14, March 2001.

Kock, N., Gray, P., Hoving, R., Klein, H., Myers, M. \& Rockart, J. (2001) Panel: IS Research Relevance Revisited: Subtle Accomplishment, Unfulfilled Promise, or Serial Hypocrisy? http://www.mis.temple.edu/kock/ICIS01

Lee, A. S. (1999a) Rigor and Relevance in MIS Research: Beyond the Approach of Positivism Alone. MIS Quarterly. Vol. 23 No. 1 March 1999, 29-33.

Lee, A. S. (1999b) The Timeliness of Publications in MIS Quarterly. ISWorld Mailing List, 6/5/1999.

Lee, A. S. (2000) Four Lessons for New Information Systems Scholars. In Keynote Address, Doctoral Consortium of Pacific Asia Conference on Information Systems, June 1 2000, Hong Kong, China. http://www.people.vcu.edu/ aslee/selectedpresentations.htm.

Lyytinen, K. (1999) Empirical Research in Information Systems: On the Relevance of Practice in Thinking of IS Research. MIS Quarterly. Vol. 23 No. 1 March 1999, 25-27.

Mead, N. R. (2000) Why Is It so Difficult to Introduce Requirements Engineering Research Results into Mainstream Requirements Engineering Practice? In Proceedings of the 4th International Conference on Requirements Engineering Schaumburg, Illinois, USA June 19-23 2000.

Medawar, P. (1963) Is the Scientific Paper a Fraud? The Listener. September 12, 377-378.

Moody, D. L. (2000) Building Links Between IS Research and Professional Practice: Improving the Relevance and Impact of IS Research. In Proceedings of International Conference on Information Systems (ICIS 2000), Brisbane, Australia, December 10-13 2000, pp. 351-360.

Mylonopoulos, N. A. \& Theoharakis, V. (2001) Global Perceptions of IS Journals. Communications of the ACM. Vol. 44 No. 9, 29-33.

Olfman, L. (2001) We ARE Doing Relevant IS Research: It's The Truth. Communications of the Association for Information Systems. Vol. 6 Article 19, March 2001. 
Paper, D. (2001) Future IS Research: The Criticality of Relevance (Editorial Preface). Journal of Information Technology Cases and Applications. Vol. 3 No. 3.

Parnas, D. L. \& Clements, P. C. (1986) A Rational Design Process: How and Why to Fake it. IEEE Transactions on Software Engineering. 12(2), 251-257.

Pike, R. (2000) Systems Software Research is Irrelevant, 1999-2000 Distinguished Lecture Series, Department of Computer Science, The University of Utah. April 11, 2000.

Press, L. (2001) IS Research Survey Results. ISWorld Mailing List, February 142001.

Robey, D. \& Markus, M. L. (1998) Beyond Rigor and Relevance: Producing Consumable Research about Information Systems. Information Resources Management Journal. Vol 11 No. 1, 7-15.

Rollier, B. (2001) Information Systems Research: Reversing the Orientation. Communications of the Association for Information Systems. Vol. 6 Article 22, March 2001.

Ruth, D. (2000) Academic Workload, Performance Appraisal and Staff Development: Difficulties of Quantification and Criteria, and the Role of Perception and Affect. Working Paper. International Centre for Development Studies, National University of Ireland, Galway.

Saunders, C. (1998) The Role of Business in IT Research. Information Resources Management Journal. Vol 11 No. 1, 4-6.

Senn, J. (1998) The Challenge of Relating IS Research to Practice. Information Resources Management Journal. Vol. 11 No. 1, 23-28.

Shannon, C. \& Weaver, W. (1949) The mathematical theory of communication. University of Illinois Press.

Straub, D. W., Ang, S., Evaristo \& Roberto (1994) Normative Standards for MIS Research. DATA BASE. Vol. 25 No. 1, 21-34.

Walstrom, K. A., Hardgrave, B. C. \& Wilson, R. L. (1995) Forums for management information systems scholars Communications of the ACM. Vol. 38 No. 3.

Westfall, R. D. (1999) An I S Research Relevance Manifesto. Communications of the Association for Information Systems. Vol. 2 Article 14 September 1999.

Westfall, R. D. (2001) Dare to Be Relevant. Communications of the Association for Information Systems. Vol. 6 Article 26, March 2001.

Whitman, M. E., Hendrickson, A. R. \& Townsend, A. M. (1999) Research Commentary. Academic Rewards for Teaching, Research, and Service: Data and Discourse. Information Systems Research. Vol. 10 No. 2, 99-109.

\section{Biography}

Michael Lang has been a Lecturer in Information Systems within the School of Business \& Economics at the National University of Ireland, Galway since 1996. Prior to that, he worked in industry as an analyst/programmer. His research interests are business systems analysis and design; hypermedia and multimedia information systems development; requirements management; and IS education. He is a B.Comm. graduate of University College Dublin, and received his M.Sc. in Applied Computing \& Information Technology from the National University of Ireland, Galway. He is currently undertaking a Ph.D. in Information Systems at University College Cork. 